\title{
Fyn Expression Predicates Both Protective Immunity and Onset of Autoimmunity
}

\author{
Behrouz Moemeni',2, Nathalie Vacaresse', Marina Vainder ${ }^{1}$, Michael E. Wortzman'2, \\ Tania H. Watts ${ }^{2}$, André Veillette ${ }^{3}$, Thomas F. Gajewski ${ }^{4}$, Michael Julius ${ }^{1,2}$ \\ ${ }^{1}$ Sunnybrook Research Institute, Toronto, Canada \\ ${ }^{2}$ Department of Immunology, University of Toronto, Toronto, Canada \\ ${ }^{3}$ Laboratory of Molecular Oncology, Clinical Research Institute of Montreal, \\ Montreal, Canada \\ ${ }^{4}$ Department of Pathology, University of Chicago, Chicago, IL, USA \\ Email: michael.julius@sri.utoronto.ca
}

Received 19 October 2015; accepted 28 November 2015; published 3 December 2015

Copyright (C) 2015 by authors and Scientific Research Publishing Inc.

This work is licensed under the Creative Commons Attribution International License (CC BY). http://creativecommons.org/licenses/by/4.0/

cC) (i) Open Access

\begin{abstract}
Genomic disruption of Fyn has not been associated with an immune-deficient phenotype, notwithstanding the profound impairment in IL-2 production by $T$ cells derived from Fyn-deficient animals observed in vitro. The results presented demonstrate that Fyn deficient animals succumb to influenza infection ahead of the protective expansion of lung infiltrating $T$ cells and viral clearance observed in wild-type hosts. Formal proof that Fyn-dependent IL-2 production mediates T cell expansion in vivo is provided using a model of $T$ cell induced enteropathy. Specifically, Fyn deficient naïve $T$ cells do not induce colitis in SCID animals due to their lack of expansion, and Fyn re-expression rescues both IL-2 production and its capacity to support in vivo expansion leading to colitis. These results reconcile the obligatory role of Fyn in T cell activation and autocrine IL-2 supported growth; and underscore the mechanism through which its function is integrated with and regulated by Lck.
\end{abstract}

\section{Keywords}

Fyn, Lck, TcR Signaling, Immunity, Autoimmunity

\section{Introduction}

FynT is the T cell specific form of Fyn, a Src Family Tyrosine Kinase involved in intracellular signal transduction [1] [2]. The role of Fyn in mediating the most proximal signals emanating from the $\mathrm{T}$ cell antigen receptor 
complex [TcR/CD3] in support of cellular activation and IL-2 mediated T cell expansion remains enigmatic. The two studies in which Fyn deficient animals were prepared and $\mathrm{T}$ cell signaling characterized revealed that TcR-induced IL-2 production, calcium flux, and proliferation assessed in vitro, were profoundly impaired [1] [2]. Further, Fyn deficient mice contain comparable numbers of peripheral T cells of both lineages [1]-[3], their T cell repertoire appears unperturbed [1]-[3] and they contain a normal complement of Tregs [3]. The only lesion described to date is absence of NK T cells [4]. The lack of an overt phenotype attributed to Fyn deficiency has supported the conclusion that Lck and Fyn are at least in part, redundant.

However, accumulating evidence supports the inter-related yet unique functions of Lck and Fyn in supporting TcR induced IL-2 production. Ordered lipid microdomains (LR) function to segregate Lck and Fyn and regulate the temporal and spatial coordination of their activation [5] [6]. Specifically, TcR-CD4 co-aggregation induces Lck activation outside LR, followed by the translocation of activated Lck into LR where it physically associates with and activates LR-resident Fyn [6] [7].

In the present study, the essential role of Fyn in TcR-mediated IL-2 production in primary T cells was formally demonstrated using an adenoviral gene delivery system. Next, the role of IL-2 in the impaired expansion of Fyn deficient T cells in vivo was formally established using a model of experimental colitis [8]-[10]. Specifically, the environmental antigen driven expansion of Fyn deficient CD45RB ${ }^{\text {hi }} \mathrm{CD}^{+} \mathrm{T}$ "inducer" cells in the large bowel of SCID recipients was virtually ablated, and rescued, along with the capacity to induce disease, upon re-expression of Fyn. Further, the capacity of anti-IL-2 to inhibit the initial expansion of colitis inducing T cells in vivo mechanistically tethers the role of Fyn in supporting TcR mediated IL-2 production in vitro with the inefficient IL-2 dependent expansion of Fyn deficient T cells in vivo and their failure to induce enteropathy.

The consequences of impaired expansion of Fyn-deficient $\mathrm{T}$ cells in vivo extend to profoundly impaired protective immunity. The immune-competence of Fyn-deficient animals was assessed using a flu infection model [11] [12]. Both wild-type and Fyn deficient hosts exhibited chronic inflammatory peribronchiolitis at day 6 and contained comparable numbers of lung infiltrating $\mathrm{T}$ cells of both lineages. The infection was cleared in wildtype hosts over the next 3 days and correlated with a 10 - 20-fold increase in infiltrating $\mathrm{T}$ cells, while Fyn deficient hosts succumbed to respiratory death due to pulmonary consolidation.

These results are first to demonstrate that the genomic disruption of fyn has profound consequences on $\mathrm{T}$ cell function in vivo; demonstrating the essential role of Fyn in TcR signaling in support of IL-2 mediated T cell expansion in vivo; and they provide the mechanistic basis underpinning the unique, yet inter-dependent roles of Lck and Fyn in the regulation of $\mathrm{T}$ cell homeostasis.

\section{Materials and Methods}

\subsection{Mice}

WT (C57BL/6), SCID, and $\mathrm{Fyn}^{-/-}$[2] were purchased from Jackson Laboratories. $\mathrm{Fyn}^{-/-}$mice were bred to CAR $\triangle 1$ [13] (here referred to as $\mathrm{CAR}^{+}$mice) in our animal facility to develop Fyn ${ }^{-/-} \mathrm{CAR}^{+}$mice. All mice, including SCID recipients, were kept in specified pathogen-free conditions prior to adoptive cell transfers. All experiments were approved by Sunnybrook Research Institute Animal Care Committee and followed guidelines set by the Canadian Council on Animal Care.

\subsection{Flu-Infection Model}

Five week old (20 grams) male mice were infected with the influenza virus A/PR8 (PR8, H1N1) through intranasal administration with either $10^{5}$ or $10^{4} \mathrm{TCID}_{50}$ in PBS as indicated. For survival experiments, following the procedure the mice were monitored daily and sacrificed when the body temperature had dropped below 32 degrees C, they had lost $>30 \%$ of total body weight, or appeared moribund. Otherwise, the mice were sacrificed at specific time points post infection.

\subsection{Viral Clearance Assay}

For viral clearance assays, lungs were excised from the animal at 3, 6, and 9 days post intranasal infection with influenza A/PR8. After weighing, lungs were homogenized in RPMI 1640 medium (1 g of lung tissue/10 ml). Supernatant was obtained and stored at $-70^{\circ} \mathrm{C}$ after centrifugation at $1200 \times g$ for 20 min at $4^{\circ} \mathrm{C}$. TCID 50 was determined by the MDCK assay with the Reed and Muench technique as previously described [14]. The infected lungs and sacrificed mice were disposed of in accordance with Sunnybrook Research Institute Animal Care 
Committee and followed guidelines set by the Canadian Council on Animal Care.

\subsection{Antibodies, Cytokines and Reagents}

Polyclonal anti-Lck and anti-Fyn antibodies have been previously described [5]. Anti-phosphotyrosine (4G10) and anti-actin antibodies were purchased from Upstate, anti-Fyb from Lifespan Bio, anti-SLP-76 (clone AS55) from Millipore, anti-CD3 $\varepsilon$ (145-2C11), anti-CD4 (GK1.5), anti-TcRC $\beta$ (H57), anti-CD69 (H1.2F3), antiCD45RB (C363.16A), anti-IL-4 (11B11), anti-IFN- $\gamma$ (R4-6A2), mouse recombinant IL-6 and recombinant human TGF- $\beta 1$ from eBiocience. Murine recombinant IL-7 was purchased from Peprotech. Anti-CAR (RmcB), anti-IL-2 (S4B6), and anti-IL-2 isotype control (rat IgG2) were isolated from their respective hybridomas cultured in our laboratory. Brij-58, Cholera toxin B-HRP (CT-HRP) and Streptavidin were purchased from SigmaAldrich.

\subsection{Cell Sorting, Cell Transfer and Isolation of Lamina Propria Lymphocytes}

Splenic $\mathrm{CAR}^{+} \mathrm{CD}^{+} \mathrm{CD}^{+} 5 \mathrm{RB}^{\mathrm{hi}}$ or $\mathrm{CD} 45 \mathrm{RB}^{\text {lo }} \mathrm{T}$ cells [11] were sorted using BDAria cell sorter and $2.5 \times 10^{6}$ cells were injected iv into each SCID recipient. After cell transfer, SCID recipients were fed non-sterile food and water and kept in cages in the absence of filter tops. Recipients were monitored and sacrificed when bloody diarrhea and/or rectal prolapse was evident. To determine the number of infiltrating donor cells, Lamina Propria lymphocytes were isolated from the large gut of recipients as described [15], stained using fluorochrome labeled anti-CD4 and anti-CAR and the number of donor cells was determined using percentage of $\mathrm{CD}^{+} \mathrm{CAR}^{+}$assessed flow cytometrically using a BD FACSCalibur.

\subsection{In Vivo CFSE Dilution Assay}

Sorted splenic $\mathrm{CAR}^{+} \mathrm{CD}^{+} \mathrm{CD}^{+} 5 \mathrm{RB}^{\mathrm{hi}} \mathrm{T}$ cells were CFSE labeled [16] and $2.5 \times 10^{6}$ cells were injected iv into each SCID recipient on day zero. Recipients also received daily intraperitoneal injections of $0.5 \mathrm{mg}$ of S4B6, 0.5 mg of isotype control, or PBS in a total volume of $200 \mu \mathrm{L}$, starting on day zero, for seven days. Recipients were sacrificed on day seven, and donor $\mathrm{CAR}^{+} \mathrm{CD}^{+} \mathrm{T}$ cells in spleen and lymph nodes were analyzed for CFSE expression flow cytometrically [16].

\subsection{Shuttle Vector Design}

The shuttle vector (pENTR-UbC) was designed by cloning human Ubiquitin C promoter [13] followed by a multiple cloning site (MCS) and a region containing the simian virus 40 late polyadenylation sequence [13] using pENTR (Invitrogen) as the vector backbone. emGFP (Invitrogen) and wild type murine FynT (WT-Fyn) [5] cDNAs were cloned into the MCS of pENTR-UbC.

\subsection{Adenoviral Constructs, Purification, Titration}

Adenoviral constructs were created using Clonase-mediated recombination between pENTR-UbC-emGFP or pENTR-UbC-WT-Fyn with pAd/PL-DEST (Invitrogen), followed by preparation of amplified adenoviral stocks according to the manufacturer's recommendations. Adenoviral stocks were purified using Adeno-X Maxi purification kits from Clontech and titered using plaque formation assays in 293A cells (Invitrogen) and Quantum's AdEasy TCID $_{50}$ protocol.

\subsection{Adenoviral Transduction}

Primary T cells were suspended at a concentration of $1 \times 10^{6}$ cells/100 $\mu \mathrm{L}$ in serum free medium [17] in the presence of adenoviral particles at a multiplicity of infection (MOI) of 10 for one hour at $37^{\circ} \mathrm{C}$. The cells were then washed and cultured in serum free medium in the presence of $10 \mathrm{ng} / \mathrm{ml}$ of IL-7 for 24 hours prior to IL-2 and IL-17A assays or for 72 hours prior to cell transfer experiments.

\subsection{Isolation of CD4+ T Cells, in Vitro CD4/TcR Coaggregation, Immunoprecipitation, Immunoblotting and Immune Complex Kinase Assay}

Splenic CD4 ${ }^{+} \mathrm{T}$ cells were isolated using EasySep negative selection kit from STEMCELL Technologies. $10^{6}$ 
$\mathrm{CD}^{+} \mathrm{T}$ cells were labeled with biotinylated H57 and/or biotinylated GK1.5 and CD4/TcR coaggregation was achieved using streptavidin as previously described [6]. The cells were lysed and subjected to immunopreciptation (IP) using anti-Lck [6]. The IP samples were subjected to immune complex kinase assay [6] and probed for Lck. For Fyb IPs, $10^{7} \mathrm{CD}^{+} \mathrm{T}$ cells were lysed and subjected to IP using anti-Fyb. The IP samples were equally divided and probed for phosphotyrosine, Fyb, SLP-76, and Fyn.

\subsection{IL-2 and IL-17A ELISA}

For IL-2, $5 \times 10^{4} \mathrm{CD}^{+} \mathrm{T}$ cells were cultured in $200 \mu \mathrm{L}$ of serum free medium [17] per well of a 96-well plate (Corning Costar) previously coated with H57 $(0.5 \mu \mathrm{g} / \mathrm{ml})$, GK1.5 $(10 \mu \mathrm{g} / \mathrm{ml})$, or both, in triplicates, for 48 hours. The level of IL-2 was determined using an IL-2 specific ELISA kit (eBioscience). For IL-17A, the cells were cultured in the presence of anti-IL-4 $(10 \mu \mathrm{g} / \mathrm{ml})$, anti-IFN- $\gamma(10 \mu \mathrm{g} / \mathrm{ml}), \mathrm{IL}-6(10 \mathrm{ng} / \mathrm{ml})$ and TGF- $\beta 1(5 \mathrm{ng} / \mathrm{ml})$ in 96-well plates (Corning Costar) previously coated with H57 $(1.5 \mu \mathrm{g} / \mathrm{ml})$, GK1.5 (30 $\mu \mathrm{g} / \mathrm{ml})$, or both, in triplicates, for 72 hours. The level of IL-17A was determined using an IL-17A specific ELISA kit (eBioscience).

\subsection{Lipid Raft Isolation}

Lipid rafts (LR) were isolated from $10^{6}$ cells, as previously described [17], and $40 \mu \mathrm{L}$ of each fraction was probed for GM1 ganglioside as a marker for lipid rafts using CT-HRP. LR distributions of Lck and Fyn were determined by immunoblotting $40 \mu \mathrm{L}$ of each fraction using anti-Lck and anti-Fyn antibodies respectively.

\subsection{Densitometry}

Densitometric analysis was performed using GS-800 densitometer and Quantity One software from Bio-Rad Laboratories on non-saturated signals.

\subsection{H \& E and Immunofluorescence}

Large intestine from SCID recipients was collected, washed with PBS, cut longitudinally, wrapped to form a roll before being frozen in OCT (Electron Microscopy Sciences), and $8 \mu \mathrm{m}$ sections were stained with hematoxylin and eosin. Pictures were taken using a DFC300 FX Digital Color Camera and the Application Suite software, both from Leica. For immunofluorescent microscopy the sections were fixed in ice-cold acetone for 10 min and air-dried at room temperature for 30 min, blocked in PBS plus 5\% normal goat serum for 30 min followed by incubation in anti-CD3 $\varepsilon$ diluted in PBS plus 5\% normal goat serum. Lastly, the sections were probed using Cy5 conjugated secondary antibody (goat anti-Armenian Hamster IgG $\left(\mathrm{H}^{+} \mathrm{L}\right)$, Jackson ImmunoResearch Laboratories) as well as 4',6-Diamidino-2-phenylindole dihydrochloride (DAPI, Sigma-Aldrich). Images were captured using a Zeiss microscope (Carl Zeiss) and analyzed using the AxioVision software (Carl Zeiss). Same time of exposure during the acquisition and same values during processing were applied to each image.

\subsection{Statistical Analysis}

$P$ values among experimental groups were determined by the unpaired Student's $t$-test.

\section{Results}

\subsection{Fyn Expression Predicates Antigen Receptor Induced IL-2 Production in CD4+ T Cells}

An in vitro assay involving antibody-mediated co-aggregation of CD4 and associated Lck with the TcR/CD3 complex was employed. $\mathrm{CD}^{+} \mathrm{T}$ cells were cultured in plates pre-coated with anti-CD4, anti-TcRC $\beta$, or both and IL-2 production was assessed at 48 hours. As has been previously described [1] [2], IL-2 production by $\mathrm{Fyn}^{-/-} \mathrm{T}$ cells was profoundly impaired, giving rise to $<10 \%$ of the IL-2 produced by WT CD4 ${ }^{+} \mathrm{T}$ cells (Figure 1).

Formal proof of the role of Fyn underpinning this defect was achieved through ectopic expression of fyn in primary resting $\mathrm{T}$ cells using an adenoviral gene delivery system. As mice do not express an adenovirus receptor, WT and $\mathrm{Fyn}^{-/}$mice were mated with those transgenic for the coxsackie/adenoviral receptor (CAR) [13]. CAR transgenic mice have been constructed to express the coxsackie/adenoviral receptor using a $\mathrm{T}$ cell specific pro- 


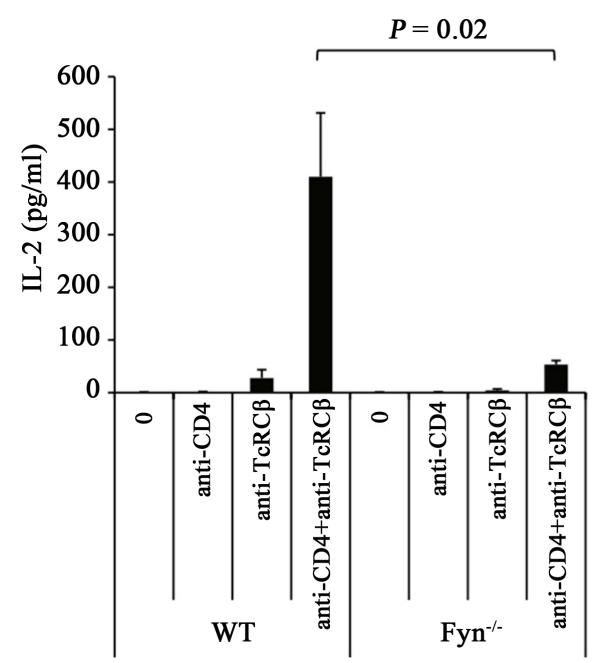

Figure 1. Profound impairment in CD4/TcR-induced IL-2 production in primary Fyn ${ }^{-1-}$
$\mathrm{CD} 4{ }^{+} \mathrm{T}$ cells. IL-2 ELISA of supernatants from primary WT or Fyn ${ }^{-1-} \mathrm{T}$ cell cultures sti-
mulated with plate-bound anti-CD4, anti-TcRC $\beta$ or both for 48 hours. Data (mean and s.d.)
represent mean values from three independent experiments.

moter to allow for the expression of CAR specifically on T cells. CAR expression in these transgenic mice is mainly restricted to $\mathrm{T}$ cells, and these animals exhibit normal $\mathrm{T}$ cell development and $\mathrm{T}$ cells expressing CAR allow for the efficient transfer of any gene of interest into primary resting T cells [13].

The efficacy of adenoviral transduction is illustrated in Figure 2. Specifically, transduction of WT CAR ${ }^{+}$ $\mathrm{CD}^{+} \mathrm{T}$ cells with GFP containing virus (Ad/GFP) resulted in $\sim 90 \% \mathrm{GFP}^{+}$cells within 24 hours (Figure 2(a)). Figure 2(b) illustrates the kinetics of ectopic expression of Fyn in $\mathrm{CD}^{+} \mathrm{Fyn}^{-/-} \mathrm{CAR}^{+}$primary T cells. Further, the levels of ectopic Fyn expression achieved in these circumstances were comparable to WT levels of endogenous Fyn expression, and there were no detectable alterations in the levels of endogenous Lck expression (Figure 2(c)). As illustrated in Figure 2(d), the cellular localization of ectopically expressed Fyn was identical to that observed for endogenous Fyn in WT cells with $>90 \%$ localizing to LR [6].

As illustrated in Figure 3, Ad/WT-Fyn transduction of Fyn ${ }^{--} \mathrm{CD}^{+}$primary $\mathrm{T}$ cells rescued levels of IL-2 production upon co-aggregation of TcR and CD4 comparable to those observed in WT CD4 ${ }^{+} \mathrm{T}$ cells. Ad/GFP transduction of either WT or Fyn ${ }^{-/}$T cells had no significant effect (Figure 3).

Previous reports have demonstrated that the activities of Lck and Fyn are reciprocally regulated [18] [19]. It is therefore possible that the impaired TcR/CD4 induced IL-2 production observed in Fyn ${ }^{-/-} \mathrm{T}$ cells is not due to the absence of Fyn per se, rather, impaired function of Lck in Fyn ${ }^{-1-} \mathrm{T}$ cells. To investigate this possibility, the activity of Lck was assessed subsequent to TcR-CD4 co-aggregation in each of three $\mathrm{CAR}^{+} \mathrm{CD} 4^{+} \mathrm{T}$ cell populations: WT or $\mathrm{Fyn}^{-/-}$transduced with Ad/GFP and Fyn ${ }^{-/}$transduced with Ad'WT-Fyn. As illustrated in Figure 4(a), both aggregation of CD4 and co-aggregation of CD4-TcR resulted in a robust and comparable induction of Lck kinase activity, in each of the three T cell populations, as assessed by levels of phosphorylation of substrate enolase. Hence, the capacity to activate Lck is not impaired in the absence of Fyn, and therefore, taken together, these results formally prove that Fyn predicates TcR induction of IL-2 production in vitro.

We next sought to characterize the signalling defect underpinning compromised IL-2 production in Fyn ${ }^{-/-} \mathrm{T}^{-/-}$ cells. Fyb is a specific Fyn substrate and it has been reported that it is not tyrosine phosphorylated in Fyn ${ }^{-/-} \mathrm{T}^{-1}$ cells [20]. As illustrated in Figure 4(b), the basal level of tyrosine phosphorylation of Fyb is indeed reduced in Fyn $^{-1-} \mathrm{T}$ cells and is restored in primary resting CD4 ${ }^{+} \mathrm{T}$ cells transduced with Ad/WT-Fyn (Figure 4(b)). However, and of note, is that notwithstanding the reduced level of PY-Fyb in Fyn ${ }^{-1} \mathrm{~T}$ cells, anti-Fyb co-immunoprecipated SLP-76 from Fyn ${ }^{-1-}$ T cells as efficiently as it did from WT T cells (Figure 4(b)). Upon TcR-mediated cellular activation, levels of P-Y Fyb and P-Y SLP-76 increase in both WT CD4 ${ }^{+} \mathrm{T}_{\text {cells }}$ and Fyn $^{-/} \mathrm{CD}^{+} \mathrm{T}$ cells transduced with Ad/WT-Fyn, but not in Fyn ${ }^{-/} \mathrm{CD}^{+} \mathrm{T}$ cells transduced with Ad/GFP (Figure 4(b)). These results confirm that Fyb is a direct Fyn substrate and also reveal the presence of a tri-molecular complex of Fyb-SLP-76-Fyn in WT and Fyn ${ }^{-1}$ T cells transduced with Ad/WT-Fyn in resting T cells. Further, that TcR mediated activation results in the parallel and Fyn-dependent increases in P-Y of both Fyb and SLP-76. 
Primary resting $\mathrm{CAD}^{+} \mathrm{CD}^{+} \mathrm{T}$ cells

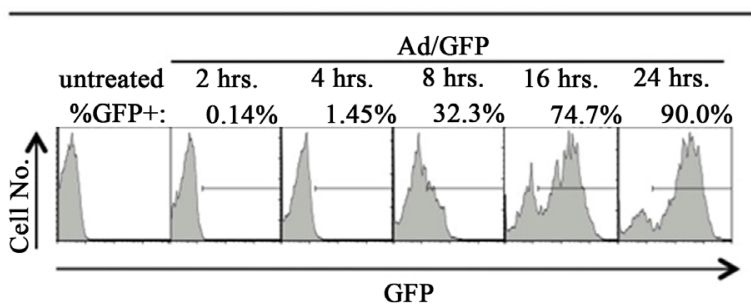

(a)

Primary resting $\mathrm{Fyn}^{--} \mathrm{CAR}^{+} \mathrm{CD} 4^{+} \mathrm{T}$ Cells

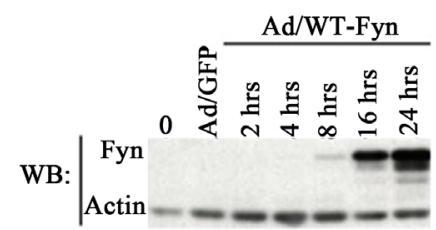

(b)

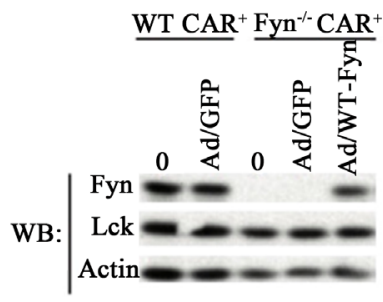

(c)

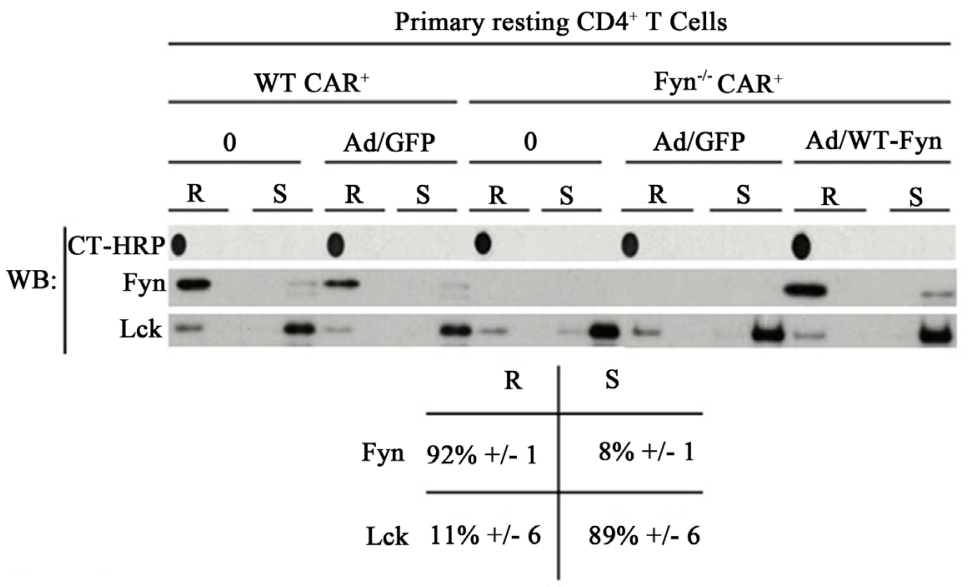

(d)

Figure 2. Efficient gene expression in primary resting $\mathrm{T}$ cells through adenoviral-mediated transduction. (a) Flow cytometric analysis of primary resting WT CAR ${ }^{+} \mathrm{CD} 4^{+} \mathrm{T}$ cells transduced with adenoviral particles encoding GFP. The percentage of $\mathrm{GFP}^{+}$cells in each sample, at the indicated time points, is shown above each histogram; (b) Western blot analysis, over the indicated time points, of primary resting $\mathrm{Fyn}^{-/-} \mathrm{CAR}^{+} \mathrm{CD} 4^{+} \mathrm{T}$ cells transduced with adenoviral particles encoding WT-Fyn. Levels of Fyn (top) and Actin (bottom) are shown; (c) Western blot analysis of WT and Fyn $^{-/-}$primary resting $\mathrm{CAR}^{+} \mathrm{CD}^{+} \mathrm{T}$ cells untreated or transduced with either Ad/GFP, or $\mathrm{Ad} /$ WT-Fyn. Presented are levels of Fyn (top), Lck (middle), and Actin (bottom), in each sample, 48 hours post transduction; (d) Western blot analysis of sucrose gradient fractions derived from WT and $\mathrm{Fyn}^{-/-}$primary resting $\mathrm{CAR}^{+} \mathrm{CD}^{+} \mathrm{T}$ cells that were untreated or transduced with either $\mathrm{Ad} /$ GFP, or Ad/WT-Fyn. Lipid raft (R) and soluble (S) fractions from each sample were probed with cholera toxin B-HRP (CT-HRP) (top), anti-Fyn (middle) and anti-Lck (bottom). The numbers represent the mean distribution of Fyn and Lck in R vs. S fractions across all samples.

\subsection{Impaired in Vivo T Cell Expansion and Disease Onset in the Absence of Fyn}

Towards mechanistically tethering the observed impairment in IL-2 production in vitro by $\mathrm{CD}^{+} \mathrm{Fyn}^{-/-} \mathrm{T}$ cells with a phenotype attributable to Fyn deficiency in an in vivo setting, we sought a model system whose endpoint was predicated by $\mathrm{T}$ cell expansion. The T cell-induced colitis model is suitable in this regard. Briefly, reconsti- 


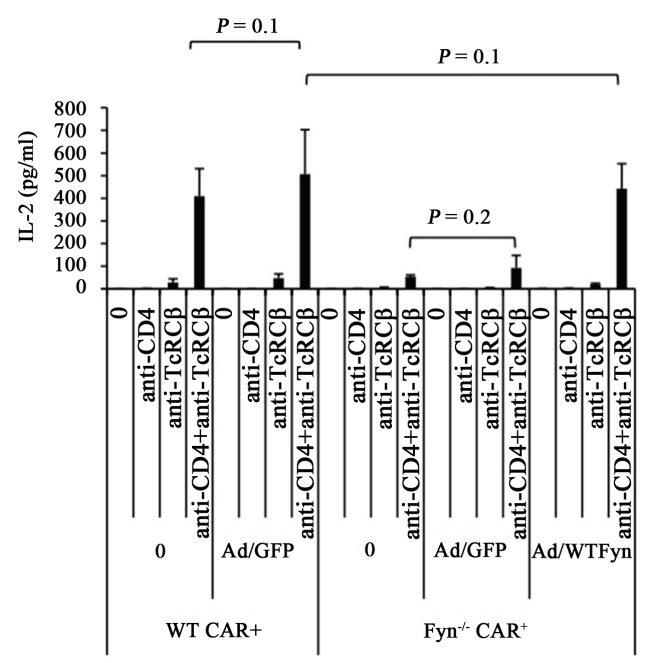

Figure 3. Fyn expression in Fyn ${ }^{-1-} \mathrm{CD}^{+} \mathrm{T}$ cells rescues CD4/TcR induced IL-2 production. IL-2 ELISA of supernatants from primary $\mathrm{CD}^{+} \mathrm{CAR}^{+}$WT or $\mathrm{Fyn}^{-1} \mathrm{~T}$ cell cultures untreated or transduced with either Ad/GFP, or Ad/WT-Fyn and stimulated with plate-bound anti-CD4, anti-TcRC $\beta$ or both, for 48 hours. Data (mean and s.d.) represent mean values from three independent experiments.

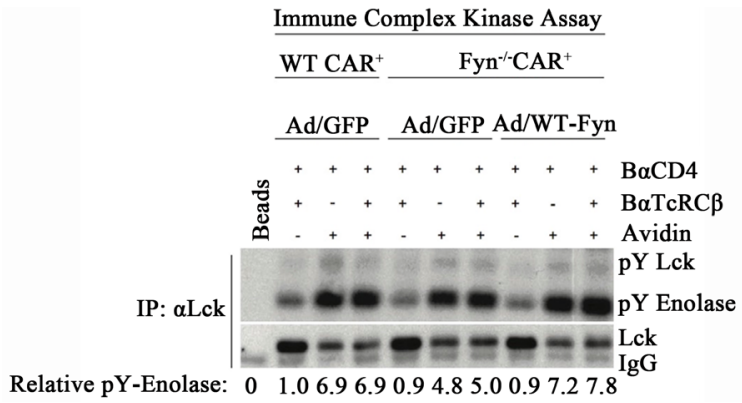

(a)

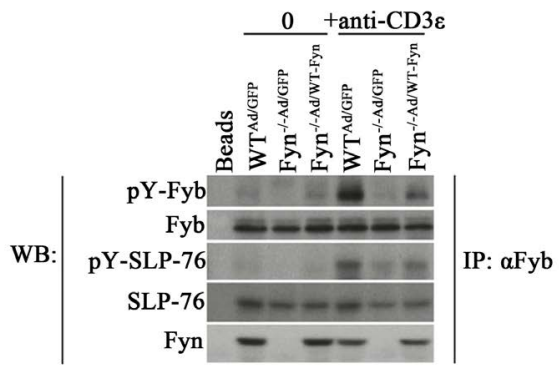

(b)

Figure 4. Fyn is not required for Lck activation but predicates tyrosine phophorylation of Fyb and SLP-76. (a) Immune complex kinase assay analysis of Lck from primary $\mathrm{CD}^{+} \mathrm{CAR}^{+}$WT or Fyn ${ }^{-1}$ T cells transduced with either Ad/GFP, or Ad/WT-Fyn. Cells were pre-coated with either biotinylated anti-CD4, biotinylated anti-TcRC $\beta$ or both, followed by addition of streptavidin or not (“+” or "-” signs respectively) for 30 seconds. Cells were lysed and Lck immunoprecipitated (IP). The top panel indicates the levels of phosphorylated Lck (pY-Lck) and phosphorylated enolase (pY-Enolase), revealed using radiolabelled $\gamma$-32P ATP. The bottom panel indicates levels of Lck from each sample assessed by western blot. Relative pY-Enolase, normalized to levels of Lck, indicates Lck kinase activity in each sample, quantified by densitometric analysis, and is represented as fold activity over background, assigned a value of 1.0; (b) Immunoprecipitation (IP) and western blot (WB) analysis of WT and $\mathrm{Fyn}^{-1-}$ primary resting CAR ${ }^{+} \mathrm{CD}^{+} \mathrm{T}$ cells transduced with either Ad/GFP or Ad/WT-Fyn. Resting cells or cells activated for 1.5 minutes using $1 \mu \mathrm{g} / \mathrm{ml}$ of anti-CD3 $\varepsilon$ (145-2C11) followed by $10 \mu \mathrm{g} / \mathrm{ml}$ of anti-Armenian Hamster IgG antibody were lysed and Fyb immunoprecipitated. Fyb immunoprecipitates were probed using anti-phosphotyrosine, anti-Fyb, anti-SLP-76, and anti-Fyn antibodies, as indicated. 
tution of severe combined immune deficient (SCID) mice with WT CD4 ${ }^{+}$CD45RB ${ }^{\text {hi }}$ T cells has been shown to cause colitis due to expansion of the injected $\mathrm{T}$ cells in the large intestine [8]-[10].

To determine whether $\mathrm{CD}^{+} \mathrm{Fyn}^{-/} \mathrm{CD} 45 \mathrm{RB}^{\text {hi }} \mathrm{T}$ cells were impaired inducers of disease, groups of SCID recipients were injected with either WT CD4 ${ }^{+} \mathrm{CD} 45 \mathrm{RB}^{\mathrm{hi}} \mathrm{T}$ cells, or the same phenotypic subset derived from $\mathrm{Fyn}^{--}$ animals. As illustrated in Figure 5(a), SCID recipients of WT naïve inducer T cells developed colitis starting at 6 weeks post injection. By 13 weeks, 100\% of the recipients of WT inducer T cells had succumbed to enteropathy. In striking contrast, recipients of Fyn deficient inducer $\mathrm{T}$ cells remained symptom free for the duration of the 16-week observation period (Figure 5(a)).

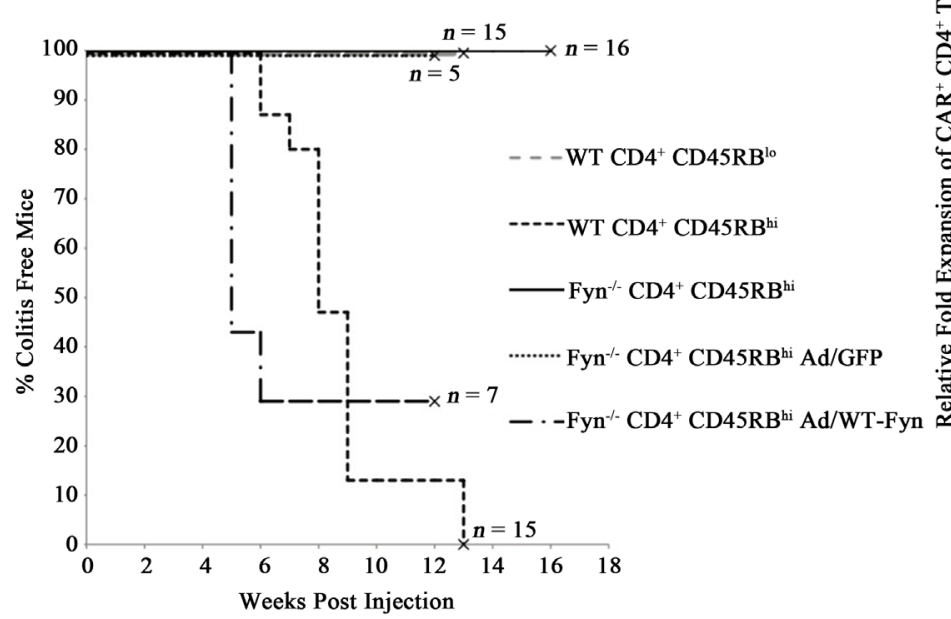

(a)

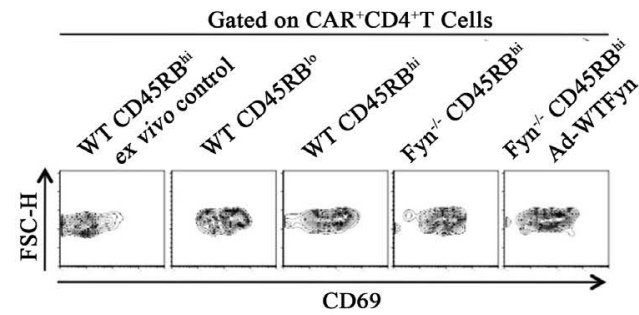

(c)

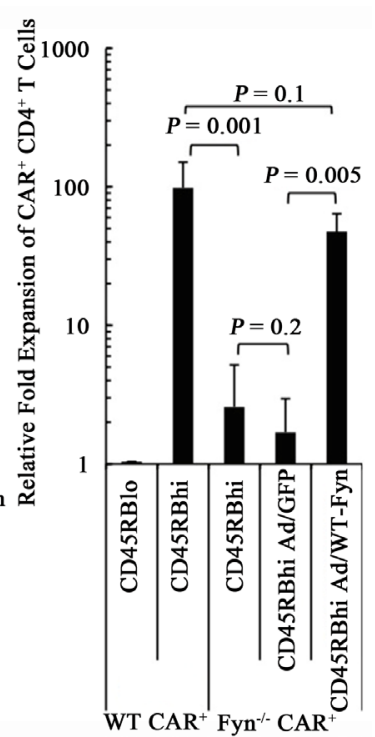

(b)

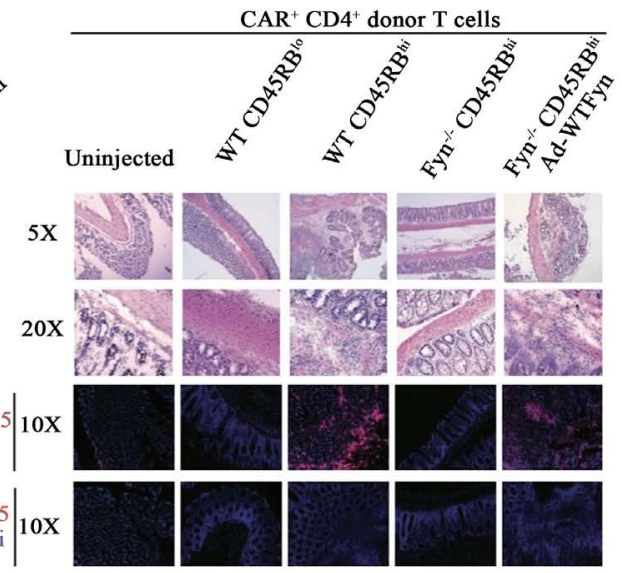

(d)

Figure 5. Impaired colitogenic capacity and in vivo T cell expansion in the absence of Fyn. (a) SCID mice were injected intravenously (iv) with $\mathrm{CAR}^{+} \mathrm{CD} 4^{+} \mathrm{CD} 45 \mathrm{RB}^{\text {hi }} \mathrm{T}$ cells from the indicated donors. Recipients were followed over time for symptoms of colitis, including bloody stool and/or rectal prolapse, and sacrificed. The graph shows the percentage of colitis free mice in each group over the indicated time period. Time of injection is indicated as week 0, "n" represents the number of animals per group, and " $x$ " indicates the end point; (b) SCID mice injected iv with either of the indicated T cell populations were sacrificed at specific time points post injection, and Lamina Propria T cells were isolated from the large intestine. The number of donor $\mathrm{T}$ cells was calculated based on CAR expression. The bar graph indicates the fold expansion of the injected cells relative to the WT CD45RB ${ }^{\text {lo }}$ population that was assigned a value of 1; (c) Flow cytometric analysis of CD69 expression by donor cells obtained in (b); (d) H\&E staining (top two panels) and immunofluorescence staining (bottom two panels) of large intestine sections from SCID mice injected with the indicated cell populations. Data (mean and s.d.) are mean values (b), or representative ((c) and (d)) of four to seven animals per group obtained from four independent experiments. 
Towards formally demonstrating that Fyn deficiency was at the root of impaired disease induction by $\mathrm{CAR}^{+} \mathrm{CD}^{+} \mathrm{Fyn}^{-/-} \mathrm{CD}_{4} \mathrm{RB}^{\text {hi }} \mathrm{T}$ cells, the latter were transduced with either Ad/GFP or Ad/WT-Fyn and their colitogenic capacity assessed. As illustrated in Figure 5, Fyn transduction restored the disease inducing capacity of $\mathrm{Fyn}^{-/-}$cells.

The symptoms correlated with profound expansion of inducer T cells rescued in the Lamina Propria of the large bowel of SCID recipients. As illustrated in Figure 5(b), colitogenic WT CD4 ${ }^{+} \mathrm{CD}_{4} \mathrm{RB}^{\mathrm{hi}} \mathrm{T}$ cells expanded

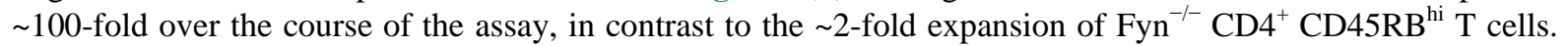
Notwithstanding the lack of expansion of $\mathrm{Fyn}^{-/-} \mathrm{T}$ cells, their upregulated expression of CD69 was comparable to that observed in WT inducer T cell populations, evidence that they were indeed engaging environmental antigens in the gut (Figure 5(c)). Figure 5(d) illustrates the characteristic histology and gut pathology induced by the WT colitigenic $\mathrm{T}$ cells, with flattening of the villi and $\mathrm{T}$ cell infiltration, not observed in recipients of their $\mathrm{Fyn}^{-/-}$counterparts. Importantly, these characteristic indicators were rescued upon ectopic expression of Fyn (Figure 5(b) and Figure 5(d)), formally demonstrating that Fyn predicated the disease inducing capacity of $\mathrm{CD}^{+} \mathrm{CD}^{\mathrm{C}} 5 \mathrm{RB}^{\text {hi }} \mathrm{T}$ cells (Figure 5(a)).

The obligate role of Fyn in supporting colitogenic $\mathrm{T}$ cells in vivo appears directly related to its role in supporting IL-2 production. As illustrated in Figure 6(a) and Figure 6(b), of the 22 cytokines assessed subsequent to TcR/CD4 co-aggregation of $\mathrm{CD}^{+}$primary T cells derived from either WT or Fyn ${ }^{-/-}$animals, only IL-2 production was significantly affected. Further, as illustrated in Figure 6(c), IL-17 production by Fyn ${ }^{-/} \mathrm{T}$ cells was within 2-fold of levels derived from WT T cells when cytokine induction was assessed in circumstances known to skew $\mathrm{CD}^{+}$responders towards Th17 cells [21] [22].

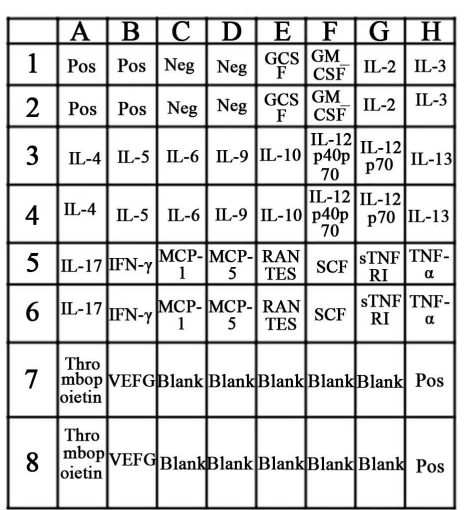

(a)

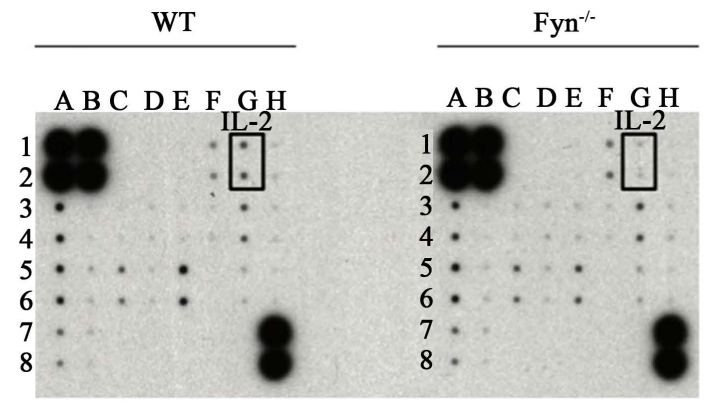

(b)

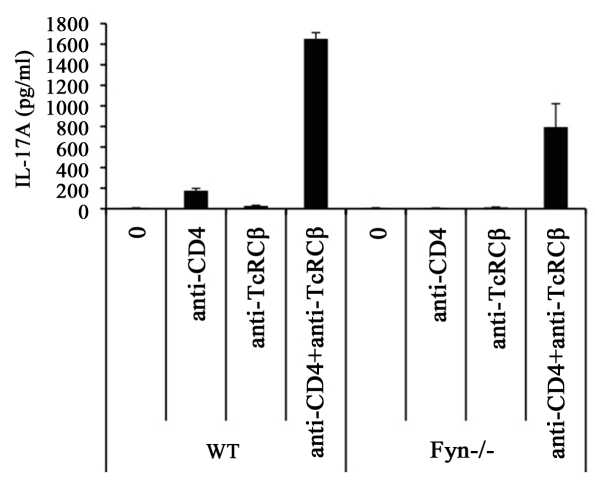

(c)

Figure 6. Role of Fyn in CD4/TcR induced cytokine production is specific to IL-2. (a) Matrix identifying the cytokines detected in cytokine array used in (b); (b) Cytokine array analysis of supernatants from primary CD4 ${ }^{+}$WT or Fyn ${ }^{-1-} \mathrm{T}_{\text {cell cul- }}$ tures stimulated with plate-bound anti-CD4 and anti-TcRC $\beta$ for 48 hours. Only cytokines at levels $>5$ fold different from those derived from WT T cells, as assessed densitometrically, are boxed; (c) IL-17A ELISA of supernatants from primary $\mathrm{CD}^{+}$WT or Fyn ${ }^{-1-} \mathrm{T}$ cell stimulated with either anti-CD4, anti-TcRC $\beta$ or both in the presence of IL-6, TGF- $\beta 1$, anti-IL-4 and anti-IFN- $\gamma$ for 72 hours. Data (mean and s.d.) are representative of two independent experiments. 


\subsection{Fyn-Dependent IL-2 Mediated Expansion of CD4+CD45RBhi T Cells in Vivo}

IL-2 mediated expansion of $\mathrm{CAR}^{+} \mathrm{CD}^{+} \mathrm{CD}^{+} 5 \mathrm{RB}^{\mathrm{hi}} \mathrm{T}$ cells was directly assessed by treating SCID recipients with 6 daily injections of PBS, mAb specific for IL-2 (S4B6), or its isotype control. As illustrated in Figure 7, $\sim 10 \%$ of donor WT CD4 ${ }^{+}$CD45RB ${ }^{\text {hi }}$ T cells rescued in the spleen and lymph nodes of these recipients had divided less than 6 times at day 7 post injection in SCID recipients treated with either PBS or isotype control. In contrast, in recipients treated with S4B6 the proportion of cells that had divided less than 6 times increased $~ 3-4$ fold (Figure 7).

Analysis of $\mathrm{Fyn}^{-/-} \mathrm{CAR}^{+} \mathrm{CD}^{+} \mathrm{CD} 45 \mathrm{RB}{ }^{\mathrm{hi}} \mathrm{T}$ cells in this assay revealed that $\sim 35 \%$ of cells divided less than 6 times, consistent with their impaired expansion in comparison to WT cells (Figure 5(b) and Figure 7). Further, anti-IL2 treatment increased the proportion of cells dividing less than 6 times to $>90 \%$ at day 7 (Figure 6). These results support the conclusion that autocrine IL-2 mediates the expansion of both WT and Fyn ${ }^{-/-} \mathrm{CD}^{+} \mathrm{T}$ cells in vivo and provides the mechanistic basis for the non-colitogenic capacity of Fyn ${ }^{-1-} \mathrm{CD}^{+} \mathrm{CD}^{+} \mathrm{RB}^{\mathrm{hi}} \mathrm{T}$ cells.

\subsection{Fyn Deficient Animals Fail to Mount a Protective Immune Response to Flu}

Fyn deficiency has not been previously associated with compromised immunity. As Fyn-dependent IL-2 production and $\mathrm{T}$ cell expansion was profoundly impaired in Fyn deficient $\mathrm{T}$ cells, we next sought to examine the impact of Fyn deficiency on immunocompetency of Fyn deficient mice in vivo, noting that IL-2, likely produced by $\mathrm{CD}^{+} \mathrm{T}$ cells, is the key cytokine involved in the early programming of naïve CD8 ${ }^{+} \mathrm{T}$ cell effector and memory differentiation [23]-[25] in circumstances of viral infection.

A flu-infection model [11] [12] was used to directly assess the immune-competence of Fyn-deficient animals. As illustrated in Figure 8(a), >90\% of Fyn-deficient hosts succumbed 7 - 8 days post infection with either dose of A/PR-8 (H1N1) used, exhibiting up to 30\% loss of body weight within the first week. In contrast, $60 \%$ of wild-type (WT) hosts survived at the higher dose and $80 \%$ at a 10 -fold lower dose of flu virus (Figure 8(a)).

Figure 8(b) illustrates lung pathology of uninfected WT; and WT and Fyn-deficient hosts at day 6 after PR-8 infection. Both WT and Fyn-deficient hosts exhibited chronic inflammatory peribronchiolitis. The WT hosts presented with minimal alveolar involvement, characterized by vascular congestion and focal inflammatory cell infiltration. In contrast, the Fyn-deficient hosts exhibited extensive and severe alveolar congestion with infiltrating blood and polymorphonuclear leukocytes; and succumbed to respiratory failure due to pulmonary consolidation (Figure 8(b)).

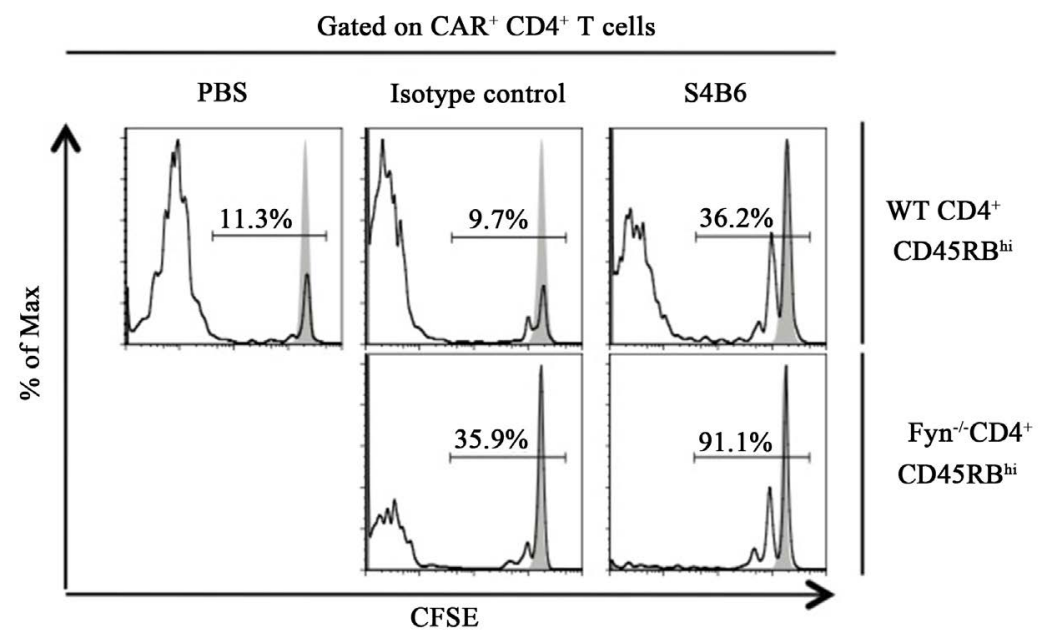

Figure 7. Fyn-dependent expansion of $\mathrm{CAR}^{+} \mathrm{CD} 4^{+} \mathrm{CD} 45 \mathrm{RB}^{\mathrm{hi}} \mathrm{T}$ cells is mediated by IL-2 in vivo. Spleens and lymph nodes of SCID recipients of $2.5 \times 10^{6}$ CSFE-labelled donor cells were harvested on day 7. Groups of recipients received daily injections of PBS, or $0.5 \mathrm{mg}$ of either anti-IL-2 mAb S4B6 or isotype control. CSFE labeling of donor cells derived from recipients treated as indicated was assessed flow cytometrically on day 7. Numbers represent percentage of cells that had undergone 0 - 5 divisions. Grey histograms indicate CSFE levels of non-stimulated cells after overnight incubation at $37^{\circ} \mathrm{C}$. Data are representative of three mice per group. 


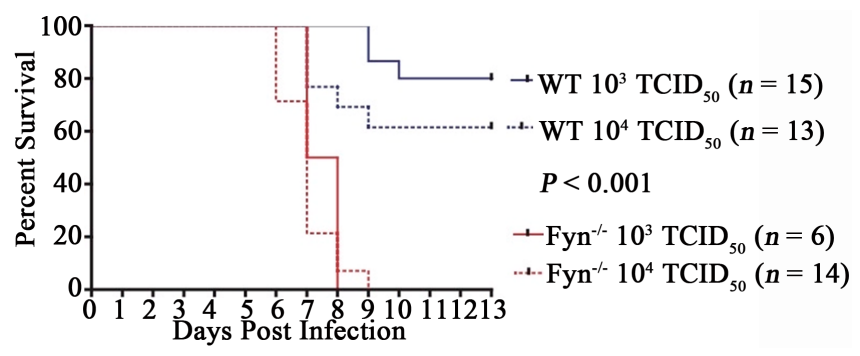

(a)

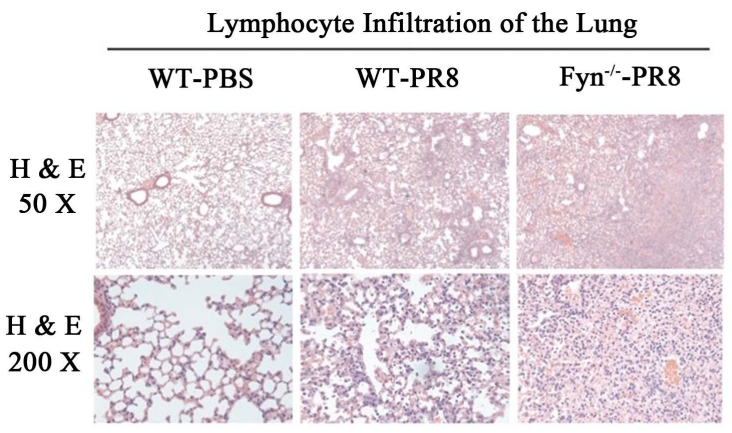

(b)

Number of Infiltrating T Cells $\left(\times 10^{4}\right)$

\begin{tabular}{|c|c|c|c|c|c|c|c|c|}
\hline \multicolumn{3}{|c|}{ WT } & \multicolumn{3}{c|}{ Fyn $^{-/}$} \\
\hline \multicolumn{3}{|c|}{ Day 6 } & \multicolumn{3}{c|}{ Day 9 } & \multicolumn{3}{c|}{ Day 6 } \\
\hline CD4 & CD8 & Tet-I & CD4 & CD8 & Tet-I & CD4 & CD8 & Tet-I \\
\hline $\begin{array}{c}0.23 \\
+/-0.072\end{array}$ & $\begin{array}{c}0.47 \\
+/-0.074\end{array}$ & $\begin{array}{c}0.052 \\
+/-0.023\end{array}$ & $\begin{array}{c}5.2 \\
+/-1.3\end{array}$ & $\begin{array}{c}4.2 \\
+/-0.73\end{array}$ & $\begin{array}{c}1.1 \\
+/-0.31\end{array}$ & $\begin{array}{c}0.34 \\
+/-0.025\end{array}$ & $\begin{array}{c}0.50 \\
+/-0.035\end{array}$ & $\begin{array}{c}0.062 \\
+/-0.024\end{array}$ \\
\hline
\end{tabular}

(c)

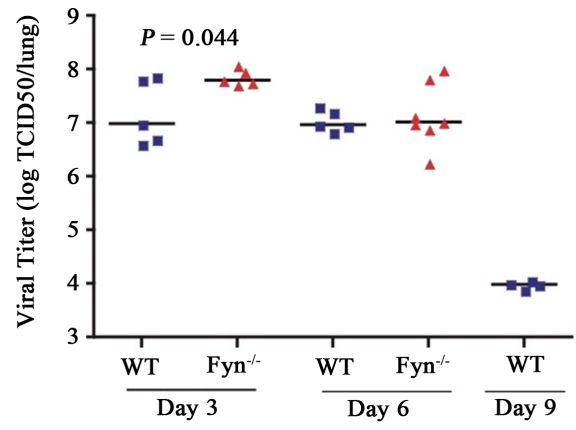

(d)

Figure 8. Fyn deficient animals fail to mount a protective immune response to flu. (a) Survival analysis of WT and Fyn ${ }^{-1-}$ mice following intranasal infection with the influenza virus A/PR8 (PR8, H1N1) at the indicated TCID 50 . " $n$ " represents the number of animals per group; (b) Immunohistochemistry analysis of lung sections from flu infected WT and Fyn ${ }^{-1-}$ mice $\left(10^{4}\right.$ TCID $\left._{50}\right)$ using H\&E staining at day 6 post infection. Data are representative of 4 animals per group; (c) Number of infiltrating $\mathrm{T}$ cells post flu infection. Lungs were analyzed flow cytometrically for the presence of $\mathrm{CD} 8 \alpha^{+} \mathrm{CD} 90^{+}, \mathrm{CD} 4^{+} \mathrm{CD} 90^{+}$, and $\mathrm{CD} 8 \alpha^{+} \mathrm{PR} 8$-specific tetramer $\mathrm{D}^{\mathrm{b}} / \mathrm{NP}_{366-374}{ }^{+} \mathrm{T}$ cells before and after flu infection at the indicated time points. The number of cells was calculated based on flow cytometric analysis and total viable lymphocyte cell counts. Data are representative of 3 animals per group; (d) Lung viral titer analysis of WT and $\mathrm{Fyn}^{-/-}$flu infected mice $\left(10^{4} \mathrm{TCID}_{50}\right)$ at indicated time points. Each square or triangle represents the value for each WT and $\mathrm{Fyn}^{-/-}$mouse, respectively, and the horizontal line represents the mean value. 
The primary immune response to PR-8 infection is known to involve both T-cell lineages as well as B-cells, all of which localize to the lung toward resolving infection [26]. Day 6 is the inflection point in the primary response reported herein. As illustrated in Figure 8(c), the number of $\mathrm{CD}^{+}$and $\mathrm{CD}^{+} \mathrm{T}$ cells localized to the lungs of infected WT and Fyn-deficient hosts is comparable at day 6 post infection; as is the frequency of contained PR8-specific CD8 ${ }^{+} \mathrm{T}$ cells (Figure 8(c)). It merits comment that flu-specific T cells of both lineages were assessed and while enumeration of $\mathrm{CD}^{+}$flu-specific $\mathrm{T}$ cells binding the dominant MHC Class I binding PR8-derived peptide was reproducible, results assessing binding of one of many MHC Class II PR8-derived peptides were not (data not shown). Notwithstanding, these results support the conclusion that neither the T cell repertoire [1]-[3] nor T cell homing capacity is compromised in the absence of Fyn.

As illustrated in Figure 8(c), the survival of WT hosts correlated with a 20-fold and 9-fold increase in the number of lung infiltrating $\mathrm{CD}^{+}$and $\mathrm{CD}^{+} \mathrm{T}$ cells, respectively, at day 9 post infection, and a concomitant 20-fold increase in the number of contained flu-specific CD8 ${ }^{+} \mathrm{T}$ cells (Figure 8(c)). Viral titers assessed over the course of PR8 infection in both WT and Fyn-deficient hosts mirrored the physiological outcome of infection. Specifically, while there was a significant difference in viral titers observed at day 3 post-infection, possibly due to Fyn-dependent differences in an innate component of the immune response [4], the viral titers at day 6 postinfection were comparable in WT and Fyn-deficient hosts (Figure 8(d)). The Fyn-deficient animals were moribund at this time point and succumbed shortly thereafter, while the primary adaptive immune response in the WT animals [26], as expected, increased over the following 3 days and resolved the viral burden (Figure 8(c) and Figure $8(\mathrm{~d})$ ).

These results provide the first physiological evidence that Fyn deficient animals are profoundly immunecompromised. As formal proof of Fyn-dependent IL-2 production underpinning in vivo CD4 ${ }^{+} \mathrm{T}_{\text {cell }}$ expansion was demonstrated in the colitis model system reported herein, a rational hypothesis underlying the observation that Fyn-deficient animals succumb to PR8 infection is that Fyn-deficient PR-8 specific T cells fail to sufficiently expand at the critical inflection point of the adaptive immune response; that in turn would suggest a central role for Fyn in T cell homeostasis.

\section{Discussion}

The results presented are the first to establish that the genomic disruption of Fyn results in immunodeficiency. They mechanistically tether the in vitro observations of profoundly impaired IL-2 production in Fyn deficient $\mathrm{T}$ cells with in vivo correlates of both protective immunity and the capacity of $\mathrm{T}$ cells to induce autoimmunity. Specifically, Fyn engagement in the earliest signalling sequelae initiated upon TcR/CD3 engagement predicates robust IL-2 production, which in turn limits $\mathrm{T}$ cell expansion in vivo and hence effective T cell immunity.

In the original studies [2], it was reported that $\mathrm{Fyn}^{-/-} \mathrm{T}$ cells did not produce detectable IL-2 in response to TcR/CD3 engagement. In the present study $\mathrm{Fyn}^{-/-} \mathrm{T}$ cells were observed to produce 5\% - 10\% the levels produced by WT T cells in vitro. Importantly, this result is consistent with and rationalizes the observation that $\mathrm{Fyn}^{-/-}$animals contain a normal complement of Tregs [3]. Further, and in this regard, it has been reported that proliferation of $\mathrm{T}$ cells from $\mathrm{Fyn}^{-1-}$ animals transgenic for a pathogen specific TcR was as robust as for $\mathrm{T}$ cells from WT TcR transgenic mice, both in vitro and in vivo [3]. In circumstances where every $\mathrm{T}$ cell is antigen specific, the cumulative IL-2 produced in support of T cell expansion could be above threshold, masking the compromised IL-2 production by each $\mathrm{T}$ cell, and sufficient to support $\mathrm{T}$ cell function in the reported assays [3]. Hence the latter study is not at odds with results presented herein.

In contrast, as demonstrated in the present study using two model systems, notwithstanding the diverse repertoire of Fyn ${ }^{-1-} \mathrm{T}$ cells, Fyn deficient animals are unable to support effective T cell function. In the flu-infection model, protective $\mathrm{T}$ cell immunity cannot be mounted as infected host succumbs to virus mediated pulmonary consolidation ahead of the required and protective expansion virus specific $\mathrm{T}$ cells that have homed to the lung. Similarly, in the SCID model of enteropathy, while Fyn deficient T cells home to the gut and recognize environmental antigens as efficiently as WT T cells as assessed by levels of CD69 expression, expansion is also profoundly impaired and as a consequence inflammation does not ensue. And importantly this model enabled the formal proof that impaired IL-2 production by Fyn ${ }^{-/-} \mathrm{T}$ cells limits in vivo expansion and in turn an effective physiological response.

This conclusion derives from two convergent results. The first is that ectopic expression of Fyn in non-colitogenic Fyn ${ }^{-/} \mathrm{CD}^{+} \mathrm{CD}^{+} \mathrm{RB}^{\mathrm{hi}} \mathrm{T}$ cells rescues both levels of expansion in the large bowel comparable to those achieved by WT CD4 ${ }^{+}$CD45RB ${ }^{\text {hi }} \mathrm{T}$ cells, and the onset of colitis. The second is that the impaired expansion of 
$\mathrm{Fyn}^{-/-} \mathrm{CD}^{+} \mathrm{CD}^{2} 5 \mathrm{RB}^{\mathrm{hi}} \mathrm{T}$ cells in vivo is coupled with the significantly enhanced efficiency with which anti-IL-2 inhibited expansion. This is likely if the IL-2 supporting expansion is endogenous, as the efficacy of anti-IL-2 mediated neutralization would be directly related to levels of IL-2 produced.

Since its discovery, IL-2 has been accepted as a major T cell growth factor [27] [28], in vitro [29], and in vivo [30]. The characterization of IL-2 and IL-2R deficient animals, however, renewed attention to the role of IL-2 in $\mathrm{T}$ cell growth, differentiation and function in vivo, some aspects of which merit discussion in the context of results presented herein.

Both IL-2 ${ }^{-/-}$and IL-2R $\mathrm{R}^{-/-}$mice, unable to produce or utilize IL-2, respectively, develop autoimmune diseases, including colitis, due to T cell expansion in the large bowel [31] [32]. Two lesions contribute to disease onset in these animals. It has been demonstrated that while thymus-derived $\mathrm{T}$ cell development proceeds in these deficient strains at virtually normal levels [32] [33], intra-intestinal T cell development is ablated [15]. These observations led to studies that demonstrated the IL-10-dependent anti-inflammatory role of some subsets of gut-derived intra-epithelial T cells [34]. The second lesion evident in the absence of either IL-2 or the capacity to utilize it is the absence of Tregs [35].

At apparent odds with results reported herein is that $\mathrm{Fyn}^{-/-} \mathrm{T}$ cells fail to induce enteropathy due to the absence of IL-2-dependent expansion in vivo. A fundamental difference in these and previous analyses of disease onset in IL-2 $2^{-/-}$and $\mathrm{IL}-2 \mathrm{R}^{-/-}$deficient animals is the ongoing production and export of $\mathrm{T}$ cells from the thymus in the latter circumstances. In the present study, the colitogenic $\mathrm{T}$ cells are limiting, and hence dependence on IL-2 mediated expansion in vivo predicates the generation of sufficient $\mathrm{T}$ cells to initiate and maintain localized inflammation in the large bowel. In support of this conclusion is the observation that limiting numbers of IL-2 ${ }^{-/}$ $\mathrm{CD} 4^{+} \mathrm{CD} 45 \mathrm{RB}^{\text {hi }} \mathrm{T}$ cells transferred to RAG-2 ${ }^{-/-}$mice were unable to cause disease [36].

The role of Fyn in specifically regulating IL-2 production is rationalized based on the signalling cascade initiated upon TcR engagement. Some Fyn associated proteins and substrates, and in turn their downstream signalling partners have been characterized, including SAP [37], Pyk2 [38], and Fyb [20]. As IL-2 production is unimpaired in T cells from SAP ${ }^{-/}$animals [39], and $\mathrm{T}$ cells from Pyk2 ${ }^{-/}$animals produce WT levels of IL-2 when optimally stimulated [40], Fyb and its binding partner, SLP-76 [41], were the focus of biochemical analyses.

Primary T cells from $\mathrm{Fyb}^{-/-}$animals exhibit impaired TcR induced IL-2 production [42], comparable to that observed in Fyn ${ }^{-/} \mathrm{T}$ cells and consistent with the obligate role of the Fyn-Fyb pathway in the IL-2 defect observed in Fyn ${ }^{-1} \mathrm{~T}$ cells. Fyn is shown to support the parallel increase in levels of tyrosine phosphorylation of both Fyb and SLP-76 upon TcR mediated cellular activation. It is of note that anti-CD3, albeit infrequently, induced marginal increases in levels of P-Y-Fyb in $\mathrm{Fyn}^{-/-} \mathrm{T}$ cells, however it did not correlate with increased IL-2 production. As this sequelae predicts, in the absence of Fyn-dependent Fyb phosphorylation the increased phosphorylation of SLP-76 is ablated, as is its role as a docking site for PLC $\gamma$ [43]. As a consequence, hydrolysis of $\mathrm{PIP}_{2}$ [44] production of $\mathrm{IP}_{3}$ and the rise in $\left[\mathrm{Ca}^{2+}\right]_{\mathrm{i}}$ is impaired [1] [2]. As activation requirements for calcineurin are then impeded, the activation and translocation of NFAT that predicates the initiation of de novo transcription of the IL-2 gene [45] is compromised.

The results presented also establish the obligate, independent, yet interrelated roles of Lck and Fyn subsequent to TcR/CD3 engagement. Specifically, Lck and Fyn reside in distinct subcellular locations in primary resting $\mathrm{CD}^{+} \mathrm{T}$ cells, with $>90 \%$ of CD4-associated Lck residing outside of LR, while $>95 \%$ of Fyn is LR-resident [6]. Upon TcR/CD4 engagement, Lck is activated and functions as a mobile signaling element, translocating into LR, where it physically associates with and is critical for Fyn activation [6] [7].

Elucidation of the functional consequences of the temporal and spatial regulation of these two kinases proffers the opportunity not only to design molecules that either promote or impede their interactions, enhancing or ablating $\mathrm{T}$ cell activation and expansion, respectively; it provides a framework to model mechanisms that regulate the involvement of multiple src family tyrosine kinases functioning in a variety of receptor-mediated signaling pathways.

\section{Acknowledgements}

We gratefully acknowledge the expert technical assistance of Gisele Knowles, Manager, Scanning Microscopy and Flow Cytometry Facility and Kirishanthy Kathirkamathamby, Manager of the Antibody Core Facility at the Sunnybrook Research Institute; the assessment of the histopathology of lung sections by Professor Sylvia L. Asa Department of Laboratory Medicine \& Pathobiology, University of Toronto; and the NIH Tetramer Facility for 
the flu-specific tetramers.

\section{Authorship Contributions}

B.M. is the primary researcher having designed and executed the experiments, and prepared the manuscript. N.V. provided technical assistance with in vivo experiments, immunohistochemistry and immunofluorescence. M.V. provided technical assistance with in vivo experiments, flow cytometry, immunohistochemistry and immunofluorescence. M.W. and T.W. provided technical support with the influenza mouse model. A.V. provided anti-Lck and anti-Fyn antibodies and expert technical advice. T.F.G. provided CAR ${ }^{+}$mice. M.J. supervised the study and provided final draft of manuscript.

\section{Disclosure of Conflict of Interest}

The authors declare no competing financial interests.

\section{References}

[1] Appleby, M.W., Gross, J.A., Cooke, M.P., Levin, S.D., Qian, X. and Perlmutter, R.M. (1992) Defective T Cell Receptor Signaling in Mice Lacking the Thymic Isoform of p59fyn. Cell, 70, 751-763. http://dx.doi.org/10.1016/0092-8674(92)90309-Z

[2] Stein, P.L., Lee, H., Rich, S. and Soriano, P. (1992) pp59 $9^{f y n}$ Mutant Mice Display Differential Signaling in Thymocytes and Peripheral T Cells. Cell, 70, 741-750. http://dx.doi.org/10.1016/0092-8674(92)90308-Y

[3] Mamchak, A.A., Sullivan, B.M., Hou, B., Lee, L.M., Gilden, J.K., Krummel, M.F., Locksley, R.M. and DeFranco, A.L. (2008) Normal Development and Activation but Altered Cytokine Production of Fyn-Deficient CD4 ${ }^{+} \mathrm{T}$ Cells. The Journal of Immunology, 181, 5374-5385. http://dx.doi.org/10.4049/jimmunol.181.8.5374

[4] Eberl, G., Lowin-Kropf, B. and MacDonald, H.R. (1999) Cutting Edge: NKT cell Development Is Selectively Impaired in Fyn-Deficient Mice. The Journal of Immunology, 163, 4091-4094.

[5] Filipp, D., Leung, B.L., Zhang, J., Veillette, A. and Julius, M. (2004) Enrichment of LCK in Lipid Rafts Regulates Colocalized Fyn Activation and the Initiation of Proximal Signals through TCR Alpha Beta. The Journal of Immunology, 172, 4266-4274. http://dx.doi.org/10.4049/jimmunol.172.7.4266

[6] Filipp, D., Zhang, J., Leung, B.L., Shaw, A., Levin, S.D., Veillette, A. and Julius, M. (2003) Regulation of Fyn through Translocation of Activated LCK into Lipid Rafts. The Journal of Experimental Medicine, 197, 1221-1227. http://dx.doi.org/10.1084/jem.20022112

[7] Filipp, D., Moemeni, B., Ferzoco, A., Kathirkamathamby, K., Zhang, J., Ballek, O., Davidson, D., Veillette, A. and Julius, M. (2008) Lck-Dependent Fyn Activation Requires C-Terminus-Dependent Targeting of Kinase-Active Lck to Lipid Rafts. Journal of Biological Chemistry, 283, 26409-26422. http://dx.doi.org/10.1074/jbc.M710372200

[8] Leach, M.W., Bean, A.G., Mauze, S., Coffman, R.L. and Powrie, F. (1996) Inflammatory Bowel Disease in C.B-17 Scid Mice Reconstituted with the CD45RB High Subset of CD4 ${ }^{+}$T Cells. American Journal of Pathology, 148, 15031515.

[9] Powrie, F., Leach, M.W., Mauze, S., Caddie, L.B. and Coffman, R.L. (1993) Phenotypically Distinct Subsets of CD4 ${ }^{+}$ T Cells Induce or Protect FROM Chronic Intestinal Inflammation in C. B-17 Scid Mice. International Immunology, 5, 1461-1471. http://dx.doi.org/10.1093/intimm/5.11.1461

[10] Powrie, F., Mauze, S. and Coffman, R.L. (1997) CD4 ${ }^{+}$T Cells in the Regulation of Inflammatory Responses in the Intestine. Research in Immunology, 148, 576-581. http://dx.doi.org/10.1016/S0923-2494(98)80152-1

[11] Ennis, F.A., Verbonitz, M., Reichelderfer, P. and Daniel, S. (1976) Recombination of Influenza A Virus Strains: Effect on Pathogenicity. Developments in Biological Standardization, 33, 220-225.

[12] Lin, G.H., Sedgmen, B.J., Moraes, T.J., Snell, L.M., Topham, D.J. and Watts, T.H. (2009) Endogenous 4-1BB Ligand Plays a Critical Role in Protection from Influenza-Induced Disease. Journal of immunology, 182, 934-947. http://dx.doi.org/10.4049/jimmunol.182.2.934

[13] Wan, Y.Y., Leon, R.P., Marks, R., Cham, C.M., Schaack, J., Gejewski, T.F. and Degregori, J. (2000) Transgenic Expression of the Coxasackie/Adenovirus Receptor Enables Adenoviral-Mediated Gene Delivery in Naive T Cells. Proceedings of the National Academy of Sciences of the United States of America, 97, 13784-13789. http://dx.doi.org/10.1073/pnas.250356297

[14] Cottey, R., Rowe, C.A. and Bender, B.S. (2001) Influenza Virus. In: Coico, R., Ed., Current Protocols in Immunology, John Wiley and Sons, Hoboken. http://dx.doi.org/10.1002/0471142735.im1911s42

[15] Poussier, P., Ning, T., Chen, J., Banerjee, D. and Julius, M. (2000) Intestinal Inflammation Observed in IL-2R/IL-2 
Mutant Mice Is Associated with Impaired Intestinal T Lymphopoiesis. Gastroenterology, 118, 880-891. http://dx.doi.org/10.1016/S0016-5085(00)70174-0

[16] Quah, B.J., Warren, H.S. and Parish, C.R. (2007) Monitoring Lymphocyte Proliferation in Vitro and in Vivo with the Intracellular Fluorescent Dye Carboxyfluorescein Diacetate Succinimidyl Ester. Nature Protocols, 2, 2049-2056. http://dx.doi.org/10.1038/nprot.2007.296

[17] Marmour, M.D. and Julius, M. (2001) Role for Lipid Rafts in Regulating Interleukin-2 Receptor Signaling. Blood, 98, 1489-1497. http://dx.doi.org/10.1182/blood.V98.5.1489

[18] Filby, A., Seddon, B., Kleczkowska, J., Salmond, R., Tomlinson, P., Smida, M., Lindquist, J.A., Schraven, B. and Zamoyska, R. (2007) Fyn Regulates the Duration of TCR Engagement Needed for Commitment to Effector Function. Journal of Immunology, 179, 4635-4644. http://dx.doi.org/10.4049/jimmunol.179.7.4635

[19] Sugie, K., Jeon, M. and Grey, H.M. (2004) Activation of Naive CD4 T Cells by Anti-CD3 Reveals an Important Role for Fyn in Lck-Mediated Signaling. Proceedings of the National Academy of Sciences of the United States of America, 101, 14859-14864. http://dx.doi.org/10.1073/pnas.0406168101

[20] da Silva, A., Rosenfield, J., Mueller, I., Bouton, A., Hirai, H. and Rudd, C. (1997) Biochemical Analysis of p120/130: A Protein-Tyrosine Kinase Substrate Restricted to T and Myeloid Cells. The Journal of Immunology, 158, 2007-2016.

[21] Bettelli, E., Carrier, Y., Gao, W., Korn, T., Strom, T.B., Oukka, M., Weiner, H.L. and Kuchroo, V.K. (2006) Reciprocal Developmental Pathways for the Generation of Pathogenic Effector TH17 and Regulatory T Cells. Nature, 441, 235238. http://dx.doi.org/10.1038/nature04753

[22] Veldhoen, M., Hocking, R.J., Atkins, C.J., Locksley, R.M. and Stockinger, B. (2006) TGF $\beta$ in the Context of an Inflammatory Cytokine Milieu Supports de Novo Differentiation of IL-17-Producing T Cells. Immunity, 24, 179-189. http://dx.doi.org/10.1016/j.immuni.2006.01.001

[23] Khanolkar, A., Fuller, M.J. and Zajac, A.J. (2004) CD4 T Cell-Dependent CD8 T Cell Maturation. Journal of Immunology, 172, 2834-2844. http://dx.doi.org/10.4049/jimmunol.172.5.2834

[24] Williams, M.A., Tyznik, A.J. and Bevan, M.J. (2006) Interleukin-2 Signals during Priming Are Required for Secondary Expansion of CD8 ${ }^{+}$Memory T Cells. Nature, 441, 890-893. http://dx.doi.org/10.1038/nature04790

[25] Wilson, E.B. and Livingstone, A.M. (2008) Cutting Edge: CD4 ${ }^{+}$T Cell-Derived IL-2 Is Essential for Help-Dependent Primary CD8 ${ }^{+}$T Cell Responses. Journal of Immunology, 181, 7445-7448. http://dx.doi.org/10.4049/jimmunol.181.11.7445

[26] Thomas, P.G., Keating, R., Hulse-Post, D.J. and Doherty, P.C. (2006) Cell-Mediated Protection in Influenza Infection. Emerging Infectious Diseases, 12, 48-54. http://dx.doi.org/10.3201/eid1201.051237

[27] Gillis, S., Ferm, M.M., Ou, W. and Smith, K.A. (1978) T Cell Growth Factor: Parameters of Production and a Quantitative Microassay for Activity. Journal of Immunology, 120, 2027-2032.

[28] Robb, R.J. and Smith, K.A. (1981) Heterogeneity of Human T-Cell Growth Factor(s) Due to Variable Glycosylation. Molecular Immunology, 18, 1087-1094. http://dx.doi.org/10.1016/0161-5890(81)90024-9

[29] Smith, K.A. (1988) Interleukin-2: Inception, Impact, and Implications. Science, 240, 1169-1176. http://dx.doi.org/10.1126/science.3131876

[30] Sojka, D.K., Bruniquel, D., Schwartz, R.H. and Singh, N.J. (2004) IL-2 Secretion by CD4 ${ }^{+}$T Cells in Vivo Is Rapid, Transient, and Influenced by TCR-Specific Competition. Journal of Immunology, 172, 6136-6143. http://dx.doi.org/10.4049/jimmunol.172.10.6136

[31] Sadlack, B., Merz, H., Schorle, H., Schimpl, A., Feller, A.C. and Horak, I. (1993) Ulcerative Colitis-Like Disease in Mice with a Disrupted Interleukin-2 Gene. Cell, 75, 253-261. http://dx.doi.org/10.1016/0092-8674(93)80067-O

[32] Willerford, D.M., Chen, J., Ferry, J.A., Davidson, L., Ma, A. and Alt, F.W. (1995) Interleukin-2 Receptor Alpha Chain Regulates the Size and Content of the Peripheral Lymphoid Compartment. Immunity, 3, 521-530. http://dx.doi.org/10.1016/1074-7613(95)90180-9

[33] Schorle, H., Holtschke, T., Hunig, T., Schimpl, A. and Horak, I. (1991) Development and Function of T Cells in Mice Rendered Interleukin-2 Deficient by Gene Targeting. Nature, 352, 621-624. http://dx.doi.org/10.1038/352621a0

[34] Poussier, P., Ning, T., Banerjee, D. and Julius, M. (2002) A Unique Subset of Self-Specific Intraintestinal T Cells Maintains Gut Integrity. Journal of Experimental Medicine, 195, 1491-1497. http://dx.doi.org/10.1084/jem.20011793

[35] Papiernik, M., de Moraes, M.L., Pontoux, C., Vasseur, F. and Penit, C. (1998) Regulatory CD4 T Cells: Expression of IL-2R Alpha Chain, Resistance to Clonal Deletion and IL-2 Dependency. International Immunology, 10, 371-378. http://dx.doi.org/10.1093/intimm/10.4.371

[36] Kameyama, K., Nemoto, Y., Kanai, T., Shinohara, T., Okamoto, R., Tsuchiya, K., Nakamura, T., Sakamoto, N., Totsuka, T., Hibi, T. and Watanabe, M. (2010) IL-2 Is Positively Involved in the Development of Colitogenic CD4 ${ }^{+}$IL-7R $^{-}$ Alpha High Memory T Cells in Chronic Colitis. European Journal of Immunology, 40, 2423-2436. 
http://dx.doi.org/10.1002/eji.200939764

[37] Latour, S., Roncagalli, R., Chen, R., Bakinowski, M., Shi, X., Schwartzberg, P.L., Davidson, D. and Veillette, A. (2003) Binding of SAP SH2 Domain to FynT SH3 Domain Reveals a Novel Mechanism of Receptor Signalling in Immune Regulation. Nature Cell Biology, 5, 149-154. http://dx.doi.org/10.1038/ncb919

[38] Qian, D., Lev, S., van Oers, N.S., Dikic, I., Schlessinger, J. and Weiss, A. (1997) Tyrosine Phosphorylation of Pyk2 Is Selectively Regulated by Fyn during TCR Signaling. Journal of Experimental Medicine, 185, 1253-1260. http://dx.doi.org/10.1084/jem.185.7.1253

[39] Davidson, D., Shi, X., Zhang, S., Wang, H., Nemer, M., Ono, N., Ohno, S., Yanagi, Y. and Veillette, A. (2004) Genetic Evidence Linking SAP, the X-Linked Lymphoproliferative Gene Product, to Src-Related Kinase FynT in $\mathrm{T}_{\mathrm{H}} 2$ Cytokine Regulation. Immunity, 21, 707-717. http://dx.doi.org/10.1016/j.immuni.2004.10.005

[40] Beinke, S.R., Phee, H., Clingan, J.M., Schlessinger, J., Matloubian, M. and Weiss, A. (2010) Proline-Rich Tyrosine Kinase-2 Is Critical for CD8 T-Cell Short-Lived Effector Fate. Proceedings of the National Academy of Sciences of the United States of America, 107, 16234-16239. http://dx.doi.org/10.1073/pnas.1011556107

[41] Veale, M., Raab, M., Li, Z., da Silva, A.J., Kraeft, S.K., Weremowicz, S., Morton, C.C. and Rudd, C.E. (1999) Novel Isoform of Lymphoid Adaptor FYN-T-Binding Protein (FYB-130) Interacts with SLP-76 and Up-Regulates Interleukin 2 Production. Journal of Biological Chemistry, 274, 28427-28435. http://dx.doi.org/10.1074/jbc.274.40.28427

[42] Griffiths, E.K., Krawczyk, C., Kong, Y.-Y., Raab, M., Hyduk, S.J., Bouchard, D., Chan, V.S., Kozieradzki, I., Oliveira-dos-Santos, A.J., Wakeham, A., et al. (2001) Positive Regulation of T Cell Activation and Integrin Adhesion by the Adapter Fyb/Slap. Science, 293, 2260-2263. http://dx.doi.org/10.1126/science.1063397

[43] Yablonski, D., Kadlecek, T. and Almeida, A.R. (2001) Identification of a Phospholipase C- $\gamma 1$ (PLC- $\gamma 1$ ) SH3 Domain-Binding Site in SLP-76 Required for T-Cell Receptor-Mediated Activation of PLC- $\gamma 1$ and NFAT. Molecular and Cellular Biology, 21, 4208-4218. http://dx.doi.org/10.1128/MCB.21.13.4208-4218.2001

[44] Meldrum, E., Parker, P.J. and Carozzi, A. (1991) The PtdIns-PLC Superfamily and Signal Transduction. Biochimica et Biophysica Acta, 1092, 49-71. http://dx.doi.org/10.1016/0167-4889(91)90177-Y

[45] Hogan, P.G., Chen, L., Nardone, J. and Rao, A. (2003) Transcriptional Regulation by Calcium, Calcineurin, and NFAT. Genes \& Development, 17, 2205-2232. http://dx.doi.org/10.1101/gad.1102703 